\title{
Supply and larval traits at metamorphosis of a coastal marine invertebrate with a bi-phasic life cycle under contrasting oceanographic conditions
}

\author{
Rey Felisa ${ }^{1,2}$, Silva Neto Gina M. ${ }^{1}$, Bueno-Pardo Juan ${ }^{3,4}$, Bispo Regina ${ }^{5}$, Calado Ricardo ${ }^{1}$
}

\author{
1 Departamento de Biologia \& CESAM \& ECOMARE, Universidade de Aveiro, Campus Universitário de \\ Santiago, 3810-193 Aveiro, Portugal \\ 2 Departamento de Química \& QOPNA, Universidade de Aveiro, Campus Universitário de Santiago, \\ 3810-193 Aveiro, Portuga \\ 3 Ifremer, STH/LBH, B.P. 70, Plouzané 29280, France \\ ${ }^{4}$ Campus de Gambelas, Centro de Ciências do Mar (CCMAR), Universidade do Algarve, 8005-139 \\ Faro, Portugal \\ 5 Departamento de Matemática, Faculdade de Ciências e Tecnologia, Universidade Nova de Lisboa, \\ 2829-516 Caparica, Portugal
}

Adresses mail : felisa.rey@gmail.com ; ginaneto11@gmail.com ; jbuenopardo@gmail.com ; regina.b.bispo@gmail.com ; rjcalado@hotmail.com

\begin{abstract}
:
Patterns of larval supply and larval condition at metamorphosis play key roles in the structure and dynamics of marine populations. Hence, biological and environmental conditions driving the dispersion of larval individuals, shape early life phenotypes, and influence their survival and post-settlement success. We performed a study over two consecutive years at Ria de Aveiro (Portugal), a coastal lagoon influenced by upwelling regimens in the North-eastern Atlantic. This study assessed the effect of contrasting oceanographic conditions on larval supply and larval traits at metamorphosis of the green crab Carcinus maenas. Crab megalopae were daily sampled and monitored in the laboratory until metamorphosis. Environmental conditions experienced by larvae in the field were estimated considering their expected planktonic larval duration, which was calculated for each individual using the size at metamorphosis and the average water temperature during larval development. Presence/absence, megalopa supply, and larval size were posteriorly modelled using generalized linear mixed models. The analysis of the two consecutive years showed haphazard patterns, revealing that both larval supply and phenotypic traits changed during and between supply seasons. The lunar cycle and environmental conditions were identified as drivers of the presence and supply of megalopae. Settlement events with weak upwelling index were influenced by sea temperature, while intense and constant upwelling events conditioned megalopa supply and performance at metamorphosis. In 2013, megalopae invaded the coastal lagoon in a more advanced physiological stage than in 2012 and/or under better nutritional conditions, probably due to stronger and more constant upwelling events during their pelagic larval life. Our results show that oceanographic processes stimulating upwelling and secondary production are sources of phenotypic variation at settlement, influencing both early benthic performance and adult population dynamics of marine organisms with bi-phasic life cycles.
\end{abstract}




\section{Highlights}

- Larval supply in coastal habitats is influenced by oceanographic processes. Moon cycle exerts a strong influence in coastal supply of megalopae. Higher megalopa supply was recorded during spring tides. Oceanographic processes stimulating upwelling promote variations in larval traits. Phenotypic larval traits condition larval performance at metamorphosis.

Keywords: Carcinus maenas, Bi-phasic life cycles, Invertebrate larvae, Phenotypic variations, Time series, Upwelling, East Atlantic, Portugal, Ria de Aveiro 


\section{Introduction}

The life-cycle of most marine animals is influenced by biotic and abiotic factors that directly and indirectly shape their phenotypes, survival, and recruitment (Calado and Leal, 2015; Pineda et al., 2009). Most of these organisms present a complex life-cycle with a larval phase inhabiting a different environment and having a much different morphology than juveniles and adults. In these cases, metamorphosis plays a pivotal role by linking radically different environments, such as shelf and coastal habitats, and physiologies. In this context, organisms occupying extraordinarily different environments during their lifetime are subject to a significant variation of environmental features, which sets a bottleneck and determines, to a great extent, the dynamics of their adult populations (Marshall and Morgan, 2011; Pechenik, 2006). However, the complexity of natural environments and the interaction of several factors makes difficult to identify causal relationships between population performance and environmental variables (Domingues et al., 2011; Shanks, 2013). This constraint is even more evident in marine species with planktonic larval dispersion and bi-phasic life cycles. Two main reasons explain this scenario: the in situ logistic limitations to secure the monitoring of complete larval periods, and the inherent difficulty of sampling in oceanic environments. Hence, although several efforts have been carried out to unravel the effect of environmental driving forces on larval pelagic development (Morgan et al., 2011; Shanks and Brink, 2005), most of the knowledge on this topic has been acquired through studies conducted in the laboratory under controlled conditions (e.g., Dawirs, 1985; Fowler et al., 2010; Sewell, 2005). This lack of knowledge on marine larval development in natural environments limits the understanding on the implications of larval life in adult population dynamics, coastal recruitment, and ecological webs. 
There is a growing body of studies offering evidence for the influence of pelagic larval history and early benthic juvenile life on the development of later benthic life stages of marine invertebrates (Giménez, 2010; Rey et al., 2016, 2015) as well as on the structuring and dynamics of adult marine populations (Shanks, 2013; Shima and Swearer, 2009). These studies suggest that larval trait-mediated effects are propagated throughout the life cycle of organisms like a cascade of effects, influencing their phenotype, performance and survival, and ultimately populations and communities (Giménez, 2010; Pechenik, 2018; Shima and Swearer, 2009). The classical way to understand marine population dynamics has been through time series analyses. Quantifying larval supply provides relevant information on temporal variations in the distribution of marine invertebrates (Domingues et al., 2011; Shanks, 2013). Several environmental factors have been studied to infer larval supply variation of marine invertebrates in coastal waters: wind and tide-driven circulation (Domingues et al., 2011; Queiroga et al., 2006), number of flood hours during darkness (Domingues et al., 2011), and oceanographic forcing (Giménez, 2010; Peteiro et al., 2011; Shanks, 2013). While some studies showed a coupling between settlement and upwelling favorable seasons (Peteiro et al., 2011; Shanks, 2013), others suggested that larval supply was not always correlated with tide-driven transport (Domingues et al., 2011; Giménez, 2010). These studies reported inconsistent results within and among years, hindering the predictability of delivery mechanisms and suggesting complex interactions driving population dynamics.

Larval fitness of marine invertebrates is influenced by maternal effects and environmental conditions experienced during larval life that will ultimately influence size at metamorphosis, planktonic larval duration (PLD), and early settlement performance (Calado and Leal, 2015). Temperature and food availability are usually 
identified as the most relevant factors shaping larval performance and survival (Giménez, 2010; Peters-Didier and Sewell, 2019; Rey et al., 2016; Torres et al., 2016). Temperature represents a key ecological factor with paramount influence on marine invertebrate larval development and metabolism (Anger, 2001; Giménez, 2011). Additionally, temporal variability in food supply or quality at different larval development stages (early versus late) may lead to different physiological responses in body size and reserves (Giménez, 2010; Peters-Didier and Sewell, 2019; Phillips, 2006) at recruitment, influencing early post-settlement performance and consequently, population dynamics.

Ria de Aveiro, as the North-western coast of the Iberian Peninsula, is integrated in the eastern Atlantic upwelling system (Fiuza et al., 1998). Upwelling events are caused by the action of northerly winds along the shelf that generate an Ekman drift directed offshore. Consequently, cooler and nutrient-rich water from depth emerges to the surface exerting a fertilization effect on coastal waters, thus promoting primary production and fueling marine food chains (Guisande et al., 2001; Huthnance et al., 2002). Upwelling events are frequent during spring and summer months, overlapping in time with the breeding season of many marine organisms. The nutrient-rich water mass promotes the occurrence of high levels of primary production, supporting a high biological diversity (Otero et al., 2009; Teixeira et al., 2011). This phenomenon is the basis for a rich marine food web, related also to an important production of commercial species that sustain a local industry of seafood and fisheries of small pelagic species such as sardine (Reis-Santos et al., 2013; Vasconcelos et al., 2010). The green crab Carcinus maenas is one of the most studied decapod species and has been used as a model organism in numerous works (Leignel et al., 2014). From an ecological point of view, specific features such as its rapid growth, high tolerance to 
environmental fluctuations, and a bi-phasic life history make C. maenas an interesting model to expand our knowledge on the drivers of population dynamics of organisms with complex life-cycles. Along North-eastern Atlantic coasts, ovigerous females of $C$. maenas release their larvae during spring and early summer (Crothers 1967, Lyons et al. 2012), with newly hatched larvae being exported to shelf waters where they develop. Larval life includes four pelagic zoeal stages followed by a megalopa which reinvades estuarine or coastal waters to settle and metamorphose into the first benthic crab stage (Domingues et al., 2011; Queiroga et al., 2006). It has been suggested that reinvasion and metamorphosis might be coupled to certain moon phases, tidal phase, and oceanographic processes (such as upwelling) without a total agreement on the processes controlling settlement success for the species (Domingues et al., 2011; Giménez, 2010). In its native range of distribution, C. maenas larval development lasts from 5 to 7 weeks (Dawirs, 1985).

In the present study, we monitored the supply of $C$. maenas megalopae during two consecutive settlement seasons (2012 and 2013) at Ria de Aveiro (Portugal), a coastal lagoon in the western margin of the Iberian Peninsula which is a region strongly affected by seasonal upwelling (Fiuza et al., 1998). Megalopae sampled during this period were monitored under laboratory conditions until metamorphosis, while interannual differences in the presence and abundance of megalopae were contrasted with environmental conditions (i.e., upwelling index and sea surface temperature) during larval development. In this study, we surveyed the influence of oceanographic processes on the larval supply of $C$. maenas and their impact on larval performance at settlement. By combining the analyses of field data and laboratorial experiments, we aimed to disentangle the influence of moon cycle, upwelling events and sea surface temperature on the supply and performance of settling megalopae. Complex larval 
supply patterns, such as those observed in the present study, are also displayed by several other coastal organisms with commercial value. Therefore, the present study aims to contribute to a more in-depth knowledge of these events and enhance knowledge-based decision practices targeting the management of valuable marine living resources.

We hypothesize that the moon cycle will play a relevant role on megalopal settlement success because of its relationship with tidal cycle. On the other hand, we hypothesize an indirect effect of the upwelling events on megalopal recruitment success and larval fitness because of its role determining food availability and quality. The larger the amount of food availability, the lower the PLD and megalopa size at metamorphosis, increasing the settlement success. Therefore, we also hypothesize a direct relationship between upwelling events and settlement and an indirect relationship between upwelling events and megalopa size at metamorphosis. Since upwelling and temperature are inversely associated, the reverse patterns are expected when looking at the effect of temperature.

\section{Material and Methods}

\subsection{Study system}

Ria de Aveiro (40 $37^{\prime} 17^{\prime}$ ' N, $8^{\circ} 44^{\prime} 56^{\prime}$ ' W) is a shallow coastal lagoon in the western margin of mainland Portugal. The lagoon circulation is mainly influenced by tides with a semidiurnal regime of ca. $12.42 \mathrm{~h}$ and a tidal range of $2 \mathrm{~m}$ at the mouth (Dias et al., 2000). Besides tides, river flows also influence, to a lesser extent, its physical dynamics, affecting salinity and water temperature (Dias et al., 2000).

\subsection{Sampling protocol and laboratory proceeding}


Megalopae of $C$. maenas were daily sampled during the settlement season over two consecutive years, 2012 and 2013, using two passive plankton nets as described by

Queiroga et al. (2006). During a period of 141 consecutive days (Julian days 67 to 207) in 2012 and 117 consecutive days (Julian days 66 to 182) in 2013, the nets were deployed during $24 \mathrm{~h}$ at a constant depth of $0.1 \mathrm{~m}$, with their entrance facing towards the inlet of the coastal lagoon. Every morning, plankton held in the collector was transported to the laboratory, where $C$. maenas megalopae were separated and counted. A maximum of ten megalopae per day were randomly chosen and reared in individual PVC containers $(\sim 300 \mathrm{~mL})$ with artificial seawater (prepared by mixing Tropic Marine ProReef salt, Tropic Marine, with purified freshwater from a reverse osmosis unit) that was fully renewed every day. All megalopae were kept under starvation and controlled conditions of temperature $\left(18^{\circ} \mathrm{C}\right)$, salinity $(35)$ and photoperiod $(12: 12 \mathrm{~h}$, light:dark). Exuviae shed at metamorphosis were preserved individually in a solution of ethyl alcohol (97\%): glycerine (8:2, by volume) for posterior morphometric analysis. Carapace length $(\mathrm{CL}$, measured from the tip of the rostrum to the posterior end of the cephalothorax) was determined to the nearest $0.01 \mathrm{~mm}$ using a stereomicroscope (SZX16, Olympus) with a calibrated micrometer eyepiece. Time to metamorphosis (TM, number of days required to perform the metamorphosis and to become a crab since megalopa invaded the coastal lagoon) was recorded each $24 \mathrm{~h}$. When megalopae died before metamorphosing (in other words, before becoming a crab), the time until death was also recorded.

Sampling days were numbered as Julian days in order to simplify the data visualization and posterior analysis.

\subsection{Environmental conditions}


Upwelling index (UI) data from Aveiro region $\left(41^{\circ} \mathrm{N}, 10.5^{\circ} \mathrm{W} ; 41.5^{\circ} \mathrm{N}, 10^{\circ} \mathrm{W}\right.$;

$41^{\circ} \mathrm{N}, 9.5^{\circ} \mathrm{W} ; 40.5^{\circ} \mathrm{N},-10^{\circ} \mathrm{W}$ ) were collected from the Instituto Español de

Oceanografia historical dataset (www. indicedeafloramiento.ieo.es) calculated as

described by González-Nuevo et al. (2014) (Fig, 1). Sea surface temperature (SST)

data were retrieved from the buoy located at Porto de Leixões $\left(41^{\circ} \mathrm{N} ; 8^{\circ} \mathrm{W}\right.$; depth 83

m) and supplied by the Instituto Hidrográfico - Marinha - Portugal (Fig. 2). 
a)

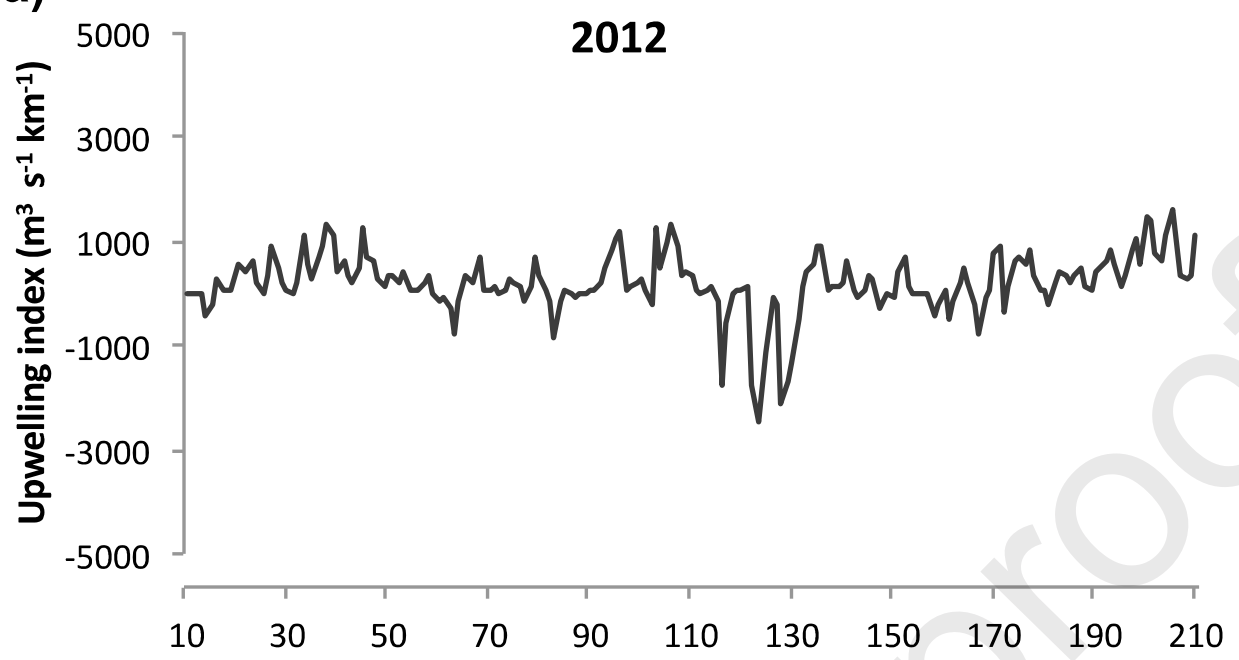

b) 2013

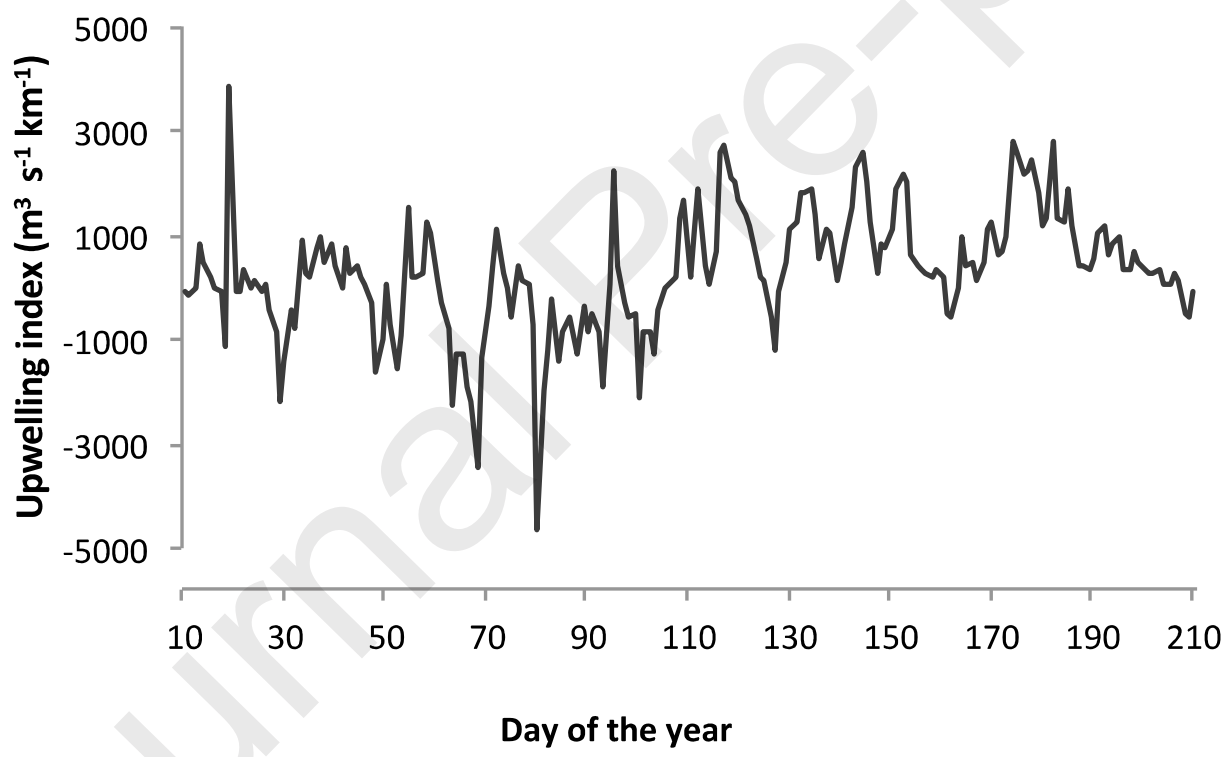

Figure 1 Time series of upwelling index in the coastal region of Aveiro (Portugal), from day 10 to 210 of a) 2012 and b) 2013 . 
a)

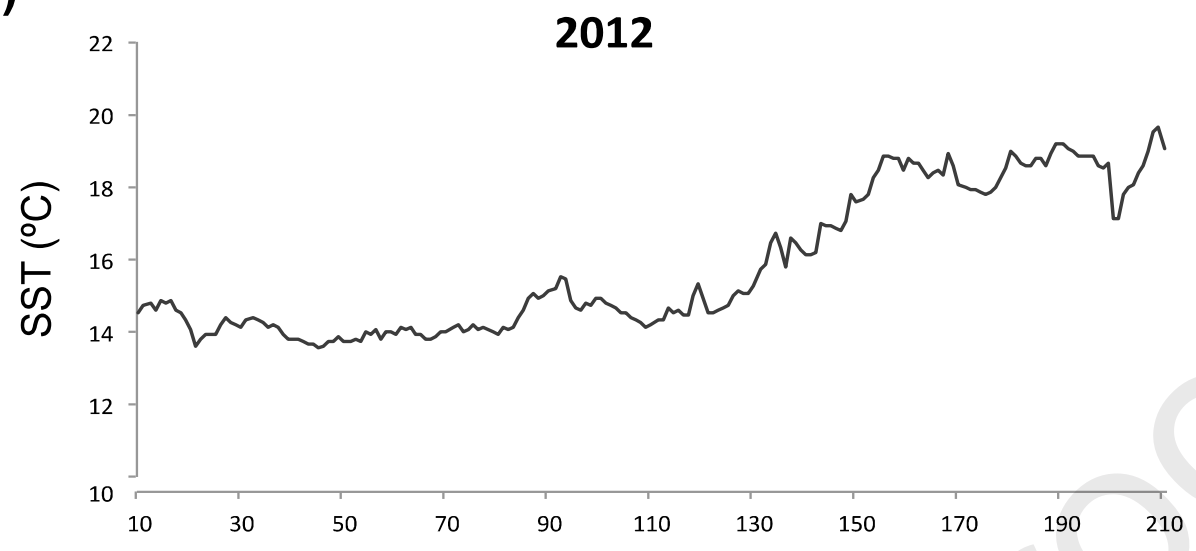

b)

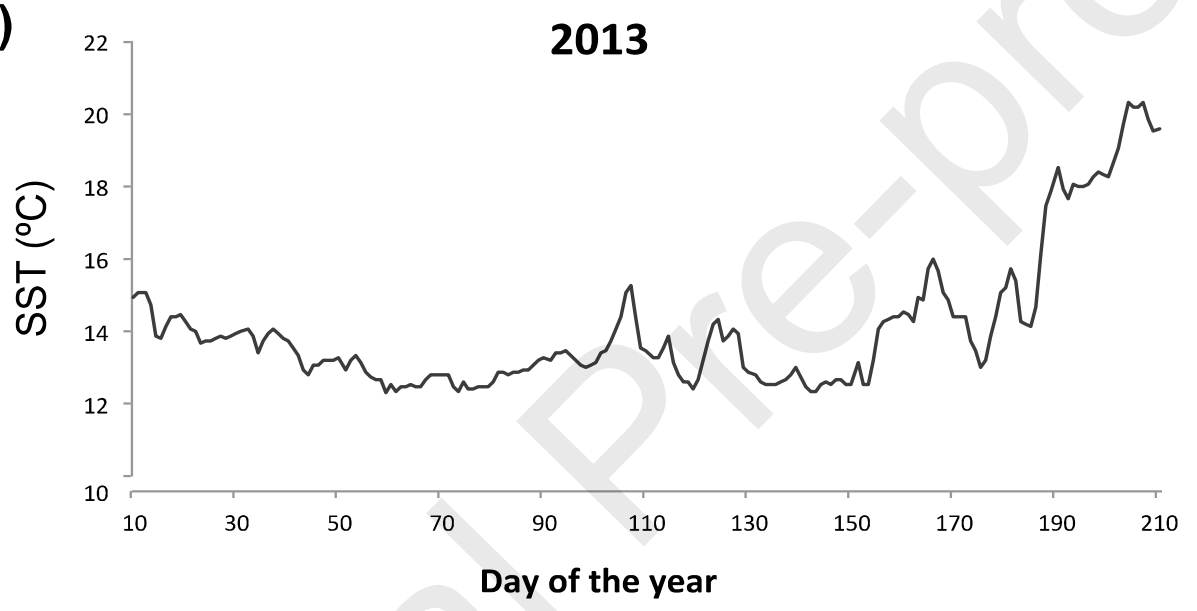

Figure 2 Time series of sea surface temperature (SST) in the harbor of Leixões (Matosinhos, Portugal), from day 10 to 210 of a) 2012 and b) 2013. 


\subsection{Planktonic larval duration (PLD) and early post-settlement performance}

The time spent by larvae in the pelagic environment (i.e., PLD) was calculated following the model presented by Gillooly et al. (2002) (Eq. 1):

$P L D=\frac{4}{a_{0}} * e^{E / k T} * B V^{\propto}$

where $4 / a_{0}$ is a constant, E represents the activation energy of metabolic reactions ( $0.65 \mathrm{eV}), \mathrm{k}$ is the Boltzmann constant, $\mathrm{T}$ is the temperature of water in Kelvin, $\mathrm{BV}$ is the biovolume of the organism at the end of development (megalopa biovolume, in our case), and $\alpha$ is the allometric exponent (1/4). To estimate the value of the constant $4 / a_{0}$ $\left(1.13 * 10^{-10}\right)$, we performed a bibliographic compilation on PLD and megalopa size of brachyuran crabs obtained in laboratorial experiments at constant rearing temperatures. This model captures the reduction of PLD caused by higher temperatures and also predicts longer developmental times for larger organisms. In our analysis, PLD for each larva was calculated considering $\mathrm{T}$ as the mean SST of the 30 days previous to sampling and biovolume as the volume of spheroids with the longer axis equal to megalopa CL and the shorter axis as 3/4 of CL. Finally, we subtracted the number of days spent by each megalopa in the laboratory until metamorphosis to the PLD obtained using Eq. 1 in order to infer the number of days spent at ocean by each larva.

\subsection{Statistical analysis}

Data were analyzed using generalized linear mixed models (GLMMs) fit by maximum likelihood estimation (Laplace approximation). The probability of finding megalopae (presence/absence model) during each settlement season was modelled considering a binomial distributional (logit link function) and megalopa supply considering a Poisson distribution (log link function). The day of the year was considered as a random effect because the supply events are not independent between days. Megalopa size was 
modelled considering Gaussian distributions. Both presence/absence and supply models were calculated independently for 2012 and 2013 using the moon phase (new moon, first quarter, full moon, last quarter), UI, and SST as explanatory variables. In these models, new moon was chosen as the reference category, as it was the moon phase with a higher megalopa supply. In the case of the megalopa supply model, exploratory data analyses showed a potential importance of outliers. Extreme outliers were defined as observations 3 interquartile ranges above the $3^{\text {rd }}$ quantile. In this study, this threshold corresponded to the $90^{\text {th }}$ percentile. Above this value there were only isolated cases of very high supplies. Therefore, abundances (megalopae per day) higher than the $90^{\text {th }}$ percentile were not considered for modelling purposes. Megalopa size model included environmental conditions (UI, SST) as explanatory variables. UI and SST consider averages of 30 days before megalopa invasion of the coastal lagoon. This time scale was selected because it was the minimum number of days with influence on the post-settlement performance of C. maenas (Rey et al., 2016). Model selection was carried out through stepwise selection, using the Akaike Information Criterion (AIC) to compare the models. Models with lowest AIC were selected as the best fit. When nested models were not significantly different, the most parsimonious model was chosen. Odds ratios of categorical variables were calculated to interpret the model coefficients in megalopa presence/absence 2012 model.

Incomplete megalopa size and PLD temporal series were calculated using missing value imputation by weighted moving average in which a linear weighting expansion to both sides of the center element of a window with 8 observations ( 4 left, 4 right) was considered. In order to inspect average temporal tendency, a polynomial smoothing spline was adjusted to the observed data. 
Mann Whitney tests were carried out to compare the size of megalopae (i.e. CL) and

PLD between years. In these comparisons, only the days of the year with five or more exuviae of megalopae preserved in good conditions were considered.

All data analyses were performed using the statistical package R (R Core Team 2016).

\section{Results}

\subsection{Megalopa presence/absence models}

The megalopa presence/absence model demonstrated that the probability of finding larvae depends on moon cycle and environmental conditions. During the sampling period of 2012 (141 consecutive days), megalopae were absent from plankton nets for 42 days, while during the sampling period of 2013 (117 consecutive days), only 15 days were registered without megalopae.

In the settlement season of 2012, the best model for the presence/absence included the moon phase and SST as significant variables, showing a negative effect of temperature on the probability of finding larvae in this year (Table 1). For details of model selection, see supplementary Table S1. In 2013 the model selected was the one that only included UI as explanatory variable (Table 1), although it was not significant. For details of model selection see supplementary Table S2. Odds ratios for 2012 are summarized in Table 2. In this sense, the 2012 model showed that the odds of finding megalopae under first quarter moons and full moons were $98 \%$ and $97 \%$ lower than the odds of finding megalopae under new moons, respectively (Table 2). 


\begin{tabular}{|c|c|c|c|c|c|c|}
\hline Response variable & $\begin{array}{l}\text { Deviance } \\
\text { explained (\%) }\end{array}$ & $\begin{array}{l}\text { Explanatory } \\
\text { variables }\end{array}$ & Estimate & Std. error & $z$ value & $p$ \\
\hline \multirow[t]{4}{*}{ Presence/Absence 2012} & 26.7 & First Quarter & -4.108 & 1.555 & -2.642 & 0.008 \\
\hline & & Full Moon & -3.504 & 1.437 & -2.439 & 0.015 \\
\hline & & Last Quarter & -1.788 & 1.247 & -1.434 & 0.152 \\
\hline & & SST & -0.515 & 0.240 & -2.147 & 0.032 \\
\hline Presence/Absence 2013 & 1.0 & UI & 0.001 & 0.003 & 0.462 & 0.644 \\
\hline
\end{tabular}

Table 1 Final generalized linear mixed models identifying the explanatory variables that predict presence/absence of megalopae during the larval supply seasons of 2012 and 2013.

Abbreviations: SST: sea surface temperature; UI: upwelling index.

\begin{tabular}{|l|l|l|l|}
\hline & \multicolumn{3}{|c|}{2012} \\
\hline & OR & 95LCL & 95UCL \\
\hline First Quarter & 0.020 & 0.001 & 0.346 \\
\hline Full Moon & 0.030 & 0.002 & 0.502 \\
\hline Last Quarter & 0.170 & 0.015 & 1.928 \\
\hline
\end{tabular}

Table 2 Odds ratios (OR) of finding megalopae in 2012 under the moon phases first quarter, full, last quarter (new moon as reference category) versus new moon. Abbreviations: 95LCL: lower 95\% confidence interval limit; 95UCL: upper 95\% confidence interval limit. 


\subsection{Megalopa supply models}

The results of the megalopa supply models indicated that there are significant differences in larval supply along settlement seasons. As it was suggested in our hypothesis, there was an indirect effect of upwelling events on megalopal settlement. The number of megalopae collected during the study period (two consecutive years) was highly variable (Fig. 3). The total number of megalopae collected by plankton nets in 2012 (1,322 megalopae, min 0 and $\max 80$, considering both planktonic nets) was ten times lower than in $2013(13,238$ megalopae, min 0 and max 1538, in both planktonic nets). Figure 4 shows the graphical representation of megalopa supply records, showing a tendency associated with moon cycle (Fig. 4). New and full moons were the phases where more megalopae entered the coastal lagoon, while first quarter and last quarter showed the lowest number of megalopae (Fig. 4). This tendency was more pronounced in 2013 (Fig. 3). However, this sample trend was only captured in the megalopa supply model during 2013 and not in 2012 (see below), likely due to the large variability of abundance in 2012 when compared to 2013. In the year 2012, the best model was the one considering moon phase and SST as significant variables (Table 3). This model registered a negative effect of SST on megalopa supply, indicating that an increasing of SST reduces the number of megalopae supplied. For details of model selection see supplementary Table S3. Additionally, the variability in the supply of megalopae in 2013 was explained by the moon phase (Table 3). This model showed that the abundance of megalopae was higher during full moon, although this variable was not significant, and lower in first and last quarter. For details of model selection see supplementary Table S4. 
a) 2012

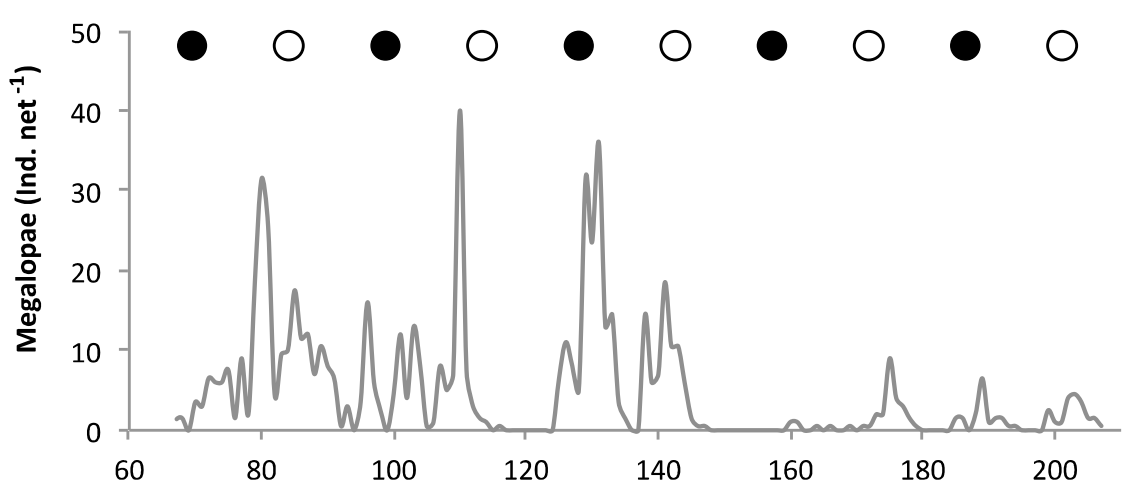

b) 2013

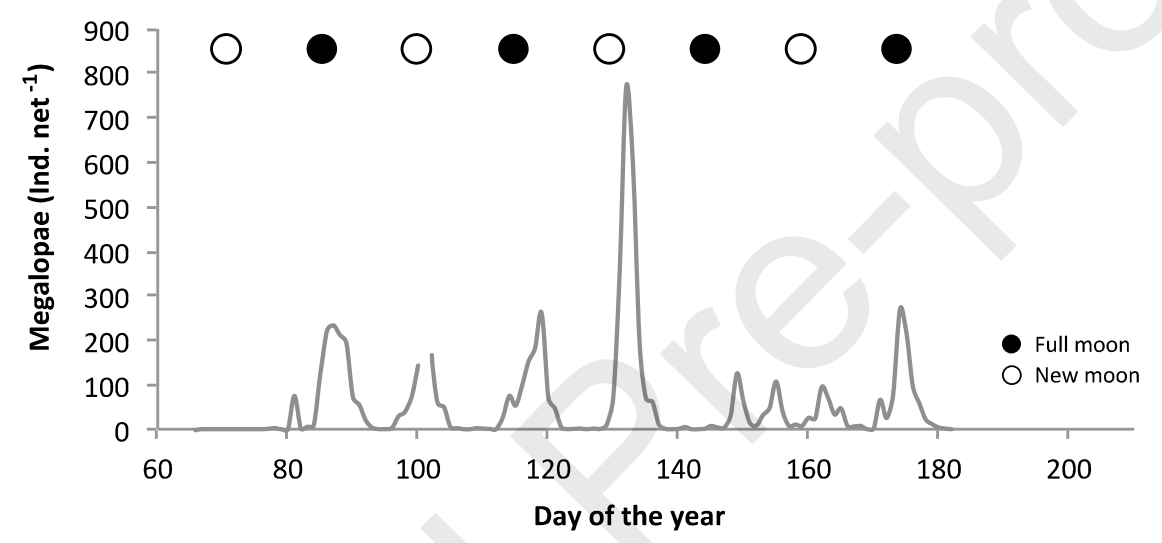

Figure 3 a) Daily average supply of Carcinus maenas megalopae at Ria de Aveiro (Portugal) during 2012 and b) 2013. 

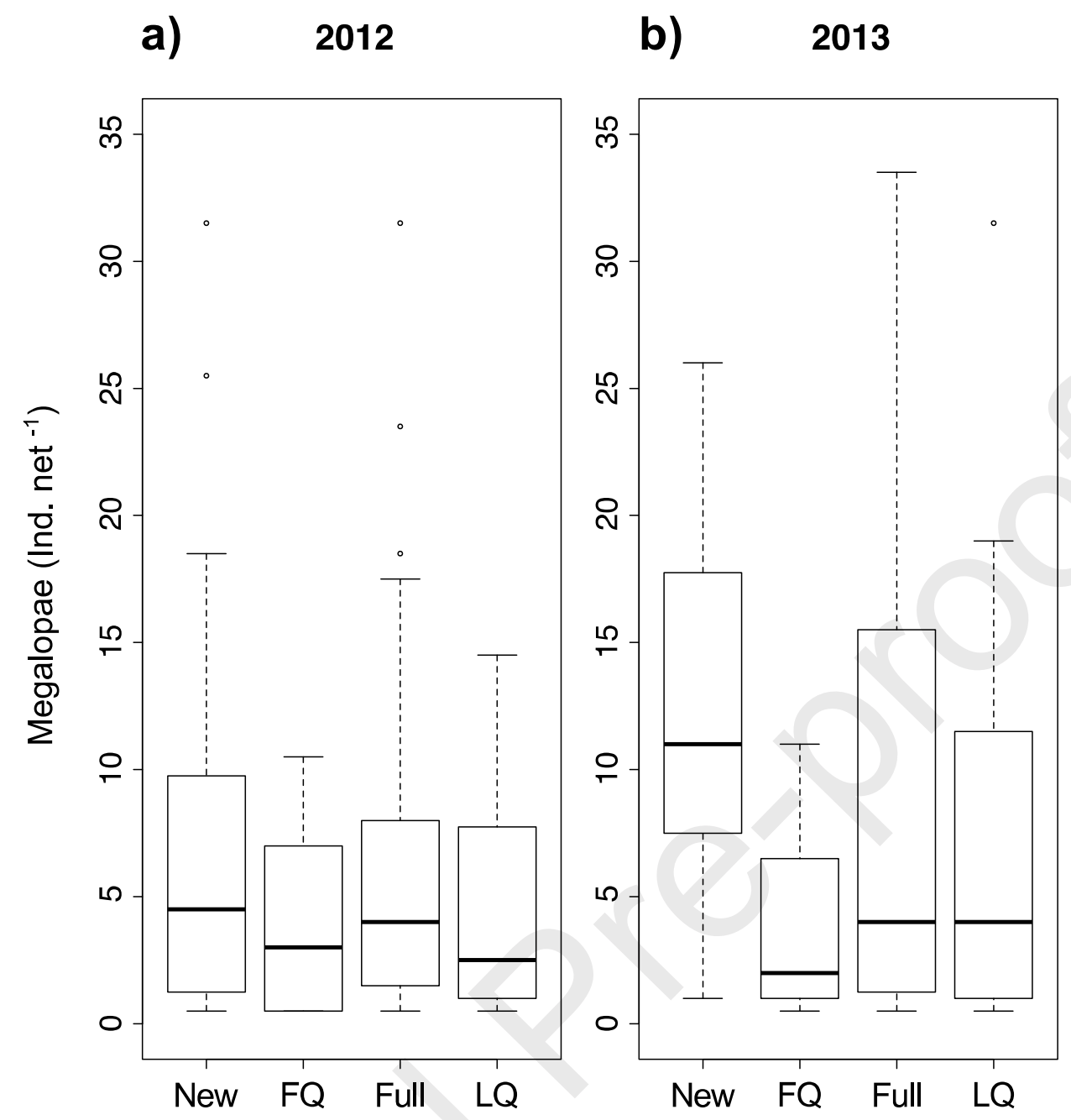

Figure 4 Supply of Carcinus maenas megalopae expressed by moon phase (new, first quarter, full and last quarter) during a) 2012 and b) 2013, at Ria de Aveiro (Portugal). 


\begin{tabular}{|c|c|c|c|c|c|c|}
\hline Response variable & $\begin{array}{l}\text { Deviance } \\
\text { explained (\%) }\end{array}$ & $\begin{array}{l}\text { Explanatory } \\
\text { variables }\end{array}$ & Estimate & Std. error & $z$ value & $p$ \\
\hline \multirow[t]{4}{*}{ Megalopa supply 2012} & 8.4 & First Quarter & -2.132 & 0.467 & -4.563 & $2.47 \mathrm{e}^{-6}$ \\
\hline & & Full & -1.365 & 0.417 & -3.271 & 0.001 \\
\hline & & Last Quarter & -0.821 & 0.397 & -2.067 & 0.039 \\
\hline & & SST & -0.586 & 0.091 & -6.412 & $1.01 \mathrm{e}^{-9}$ \\
\hline \multirow[t]{3}{*}{ Megalopa supply 2013} & 2.4 & First Quarter & -1.887 & 0.721 & -2.618 & 0.009 \\
\hline & & Full & 1.348 & 0.700 & 1.926 & 0.054 \\
\hline & & Last Quarter & -0.383 & 0.715 & -0.536 & 0.592 \\
\hline
\end{tabular}

Table 3 Final generalized linear mixed models identifying the explanatory variables that predict megalopa supply during 2012 and 2013.

Abbreviations: SST: sea surface temperature; UI: upwelling index.

\subsection{Megalopa size model and planktonic larval duration}

The presence of more intense upwelling events in 2013 could be the cause of a better larval fitness during this settlement season, because of this oceanographic process influences food availability and quality. If so, then our initial hypothesis of an indirect relationship between upwelling events and megalopa size at metamorphosis was accepted. Significant differences in larval size and PLD of megalopae invading the coastal lagoon were registered along different supply events. Megalopa size was significantly $(p<0.001)$ larger during $2012(1.39 \pm 0.07 \mathrm{~mm})$ than during $2013(1.35 \pm$ $0.08 \mathrm{~mm}$ ). Megalopa size models showed high variability during settlement periods (Fig. 5.a), which was explained by SST in 2012 and UI in 2013, both significant variables (Table 4). For details of model selection see supplementary Tables S5 and 
S6, respectively. A decrease in the PLD estimated was recorded during both years (Fig. 6.a), notwithstanding PLD in 2013 being significantly higher than in $2012(p<0.001)$. The specimens that colonized the coastal lagoon in 2012 spent between 26 - 44 days in the plankton, while the larvae of 2013 displayed a PLD estimated to be between 43 48 days (Fig. 6.a). 


\begin{tabular}{lllllll}
\hline Response variable & Deviance & Explanatory & Estimate & Std. error & $\boldsymbol{t}$ value & $\boldsymbol{P}$ \\
& explained (\%) & variables & & & & \\
\hline Megalopa size 2012 & 0.5 & SST & -0.011 & 0.004 & -2.645 & 0.010 \\
Megalopa size 2013 & 0.8 & UI & $2.75 \mathrm{e}^{-5}$ & $7.73 \mathrm{e}^{-6}$ & 3.551 & $6.000 \mathrm{e}^{-4}$ \\
\hline
\end{tabular}

Table 4 Final models for megalopa size during 2012 and 2013.

Abbreviations: SST: sea surface temperature; UI: upwelling index. 

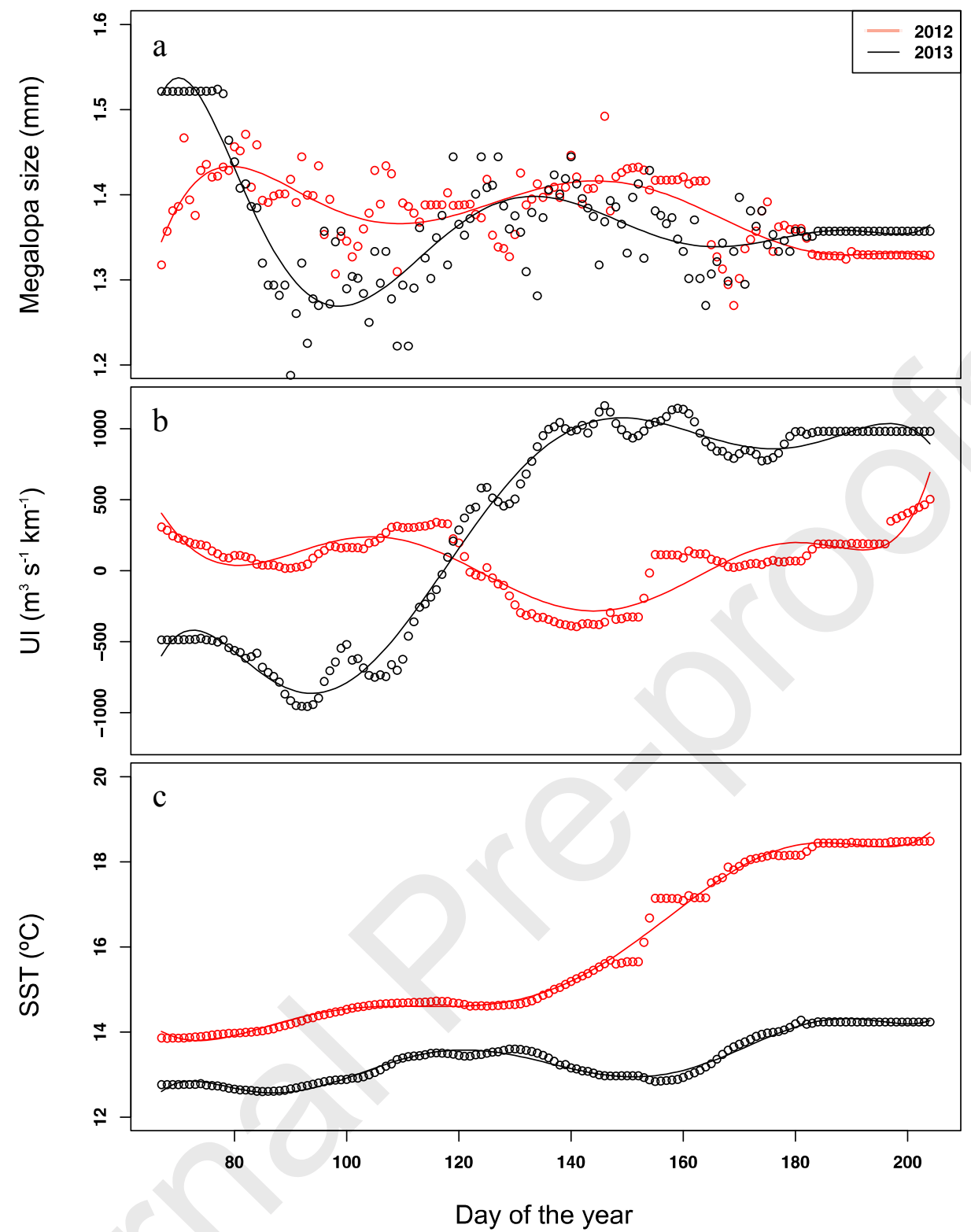

Figure 5 a) Daily average of megalopa size of Carcinus maenas (with missing value importation and smoothing spline adjustment), b) upwelling index (UI) and c) sea surface temperature (SST) during 2012 and 2013. UI and SST consider daily averages of 30 days before megalopae invaded the coastal lagoon. 


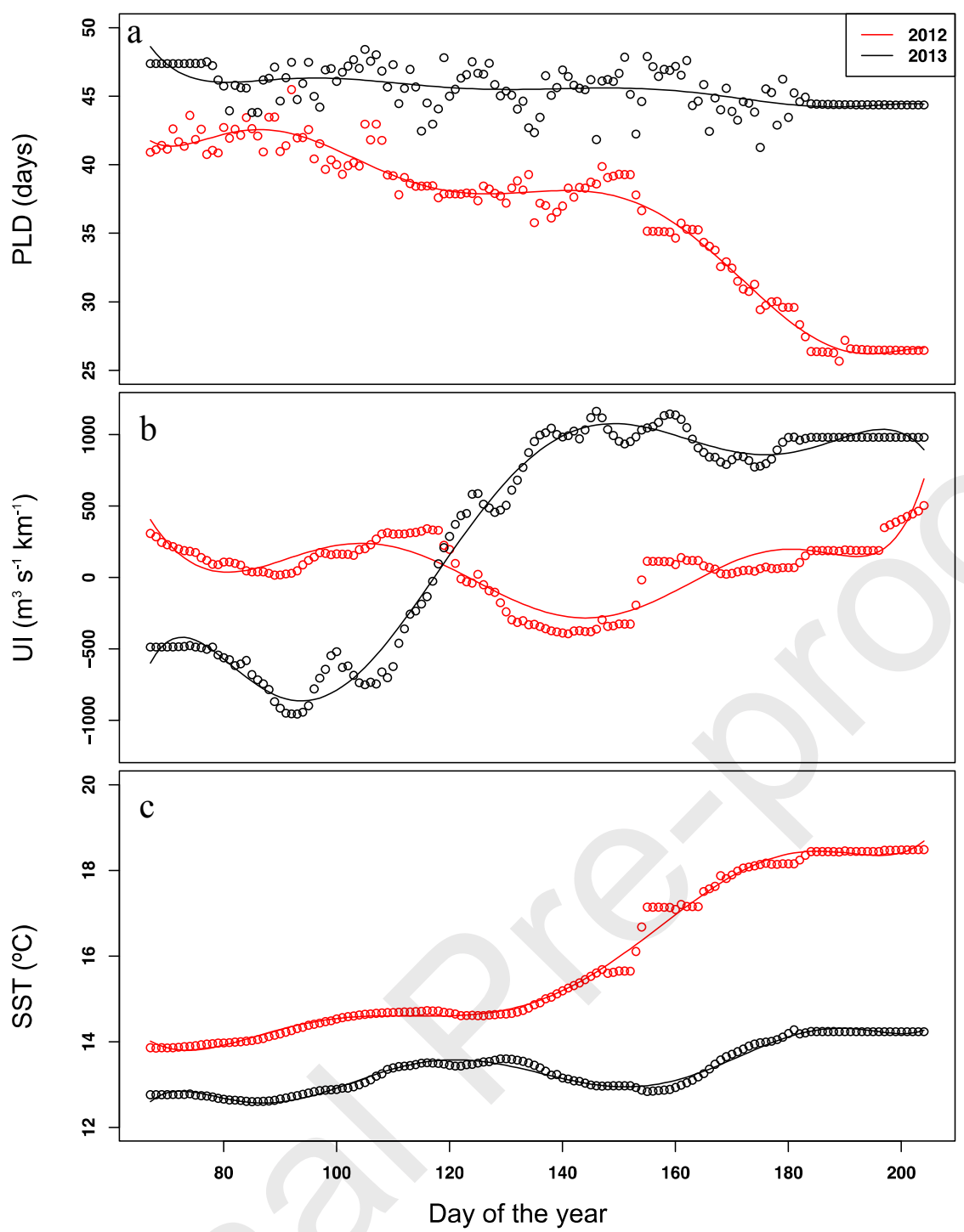

Figure 6 a) Daily average of planktonic larval duration (PLD) of Carcinus maenas

(with missing value importation and smoothing spline adjustment), b) upwelling index (UI) and c) sea surface temperature (SST) during 2012 and 2013. UI and SST represent daily averages of 30 days before megalopae invaded the coastal lagoon. 


\subsection{Early post-settlement performance}

Laboratorial experiments showed significant differences in physiological and nutritional stages of megalopae invading the coastal lagoon in different supply events. Most larvae performed metamorphosis under starvation conditions in the laboratory, showing a high survival rate (86\% in 2012 and 92\% in 2013) (Fig. 7). In both years, the average number of days that megalopae required to successfully metamorphose after invading the coastal lagoon was the same ( $4 \pm 2$ days; min 1day and max 12 days). However, the day of maximum metamorphosis varied between years. While in $201240 \%$ of megalopae metamorphosed between the $4^{\text {th }}$ and $5^{\text {th }}$ day, in 2013 more than half of the larvae metamorphosed between the $2^{\text {nd }}$ and $3^{\text {rd }}$ day. Megalopae that died prior metamorphosis, before reaching the crab stage, spent $5 \pm 2$ days (min 1 and $\max 11)$ in 2012 and $5 \pm 4$ days (min 1 and $\max 21)$ in the laboratory in 2013. It is worth highlighting that while in 2012 the maximum lifetime recorded before death in the laboratory was solely 12 days post sampling, in 2013 some megalopae remained alive up to 21 days (Fig. 7). 
a)

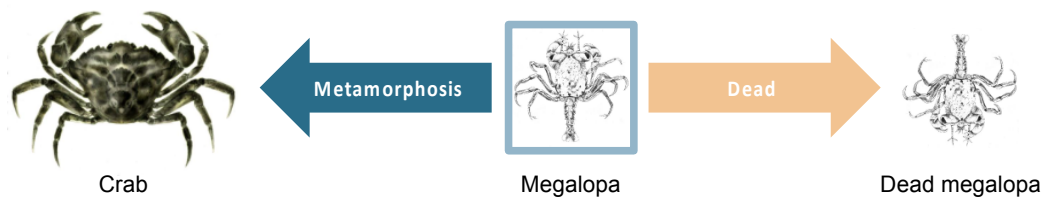

b)

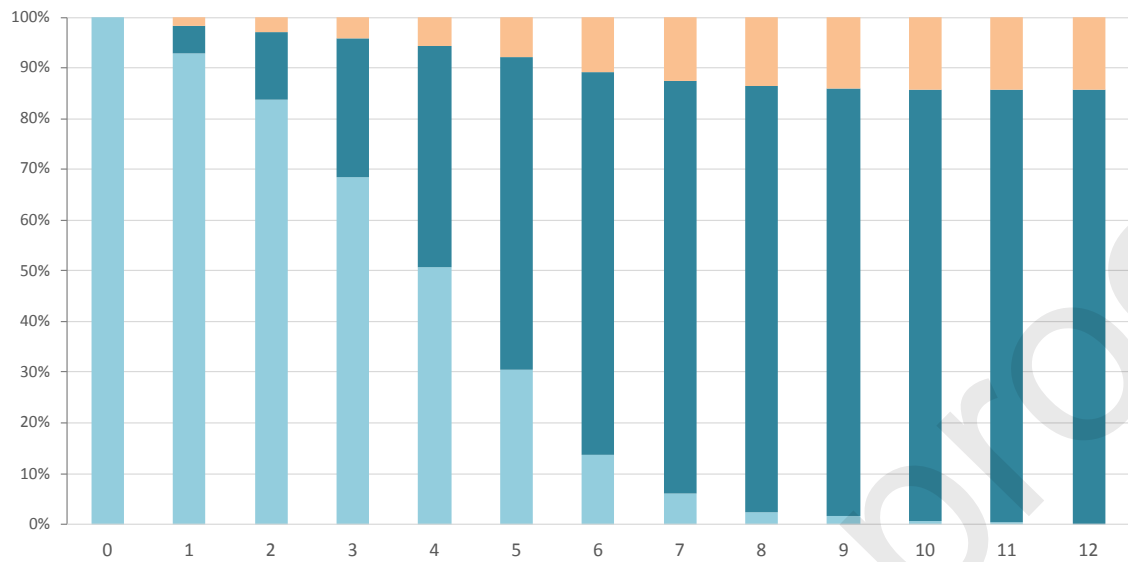

c)

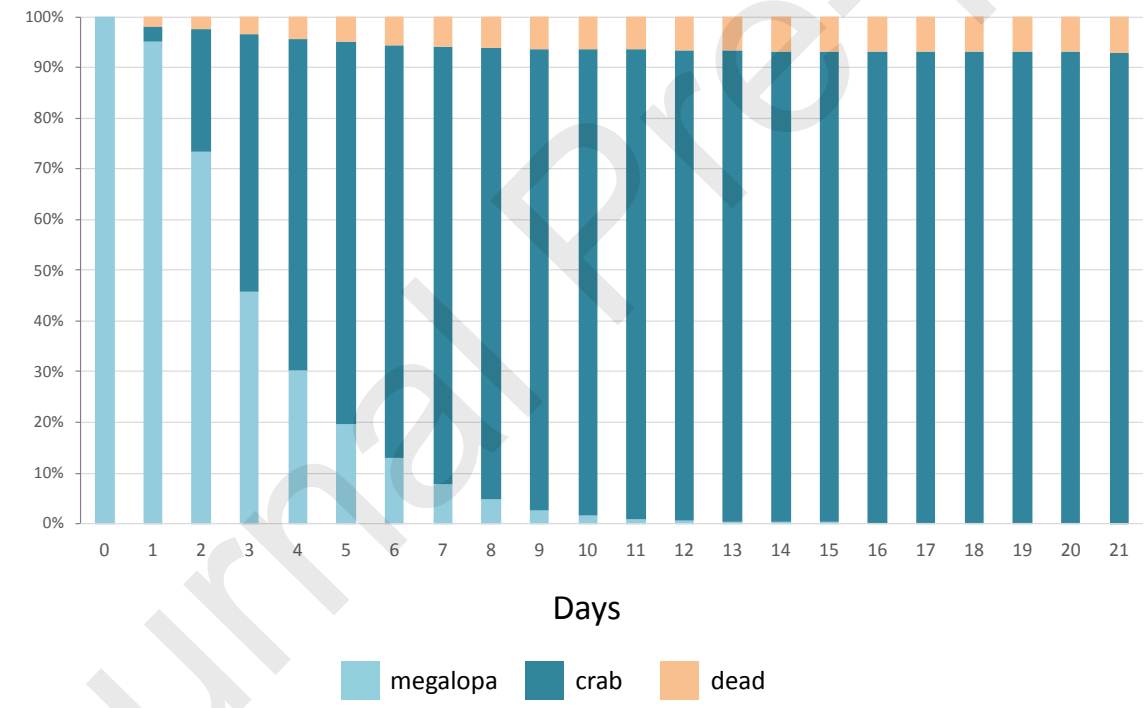

Figure 7 a) Schematic representation of megalopae monitoring in the laboratory until perform metamorphosis or died. b) Number of days spent by megalopae in the laboratory before metamorphosis or until dying in 2012 and c) 2013. $n=668$ in 2012 and $n=1240$ in 2013 . 


\section{Discussion}

The complexity of the Western Iberian coast, the nature of the oceanographic regimens, and the wind-driven circulation play an intricate role in the physical forcing of larval supply to the coast (Marta-Almeida and Dubert, 2006; Peliz et al., 2002). In this sense, the interannual comparison performed in the present study confirmed the existence of haphazard patterns that promote quantitative and qualitative shifts in the number and phenotype of larvae being supplied to coastal habitats over different periods (Domingues et al., 2011; Giménez, 2010; Shanks, 2013). The factors captured by the presence/absence and abundance models were uniform between the two years surveyed. During 2012, upwelling was weak and SST rose, likely promoting a poorer larval performance in the plankton and, consequently, resulting in a lower number of megalopae invading coastal waters. Therefore, in 2012, SST had a stronger signal than UI. On the other hand, in 2013, strong upwelling events favored a better larval performance, which resulted in a higher supply of megalopae. The presence of SST and UI as explanatory variables in several models highlights the key role of environmental conditions in marine invertebrate life cycles. Nevertheless, these models show that recruitment and population dynamics represent complex processes where multiple factors are contributing and interacting over long spatial and temporal scales (Pineda et al., 2009; Shanks, 2013). Nonetheless, both years presented a tendency associated with lunar cycle, with this trend being more evident in 2013. The supply of megalopae during 2013 displayed the typical 2-week pattern detected by other authors in meso-tidal systems (Domingues et al., 2011; Moser and Macintosh, 2001; Paula et al., 2001) which is associated with a semilunar periodicity. New and full moon tides display the largest tidal amplitudes during the lunar cycle, and thus increase the chances of megalopae to invade coastal habitats, such as estuaries and coastal lagoons 
(Queiroga et al., 2006). While during the larval supply period of 2012 the semilunar pattern was not as perceptible as in 2013 (which may be due to the lower number of megalopae supplied), it is still possible to identify a temporal pattern between maximum supply events. In this sense, higher numbers of larvae were supplied during spring tides, particularly those occurring during new moon. As it was already suggested by Domingues et al.(2011), C. maenas megalopae are not fully neustonic organisms and they develop a behavioral response to changes in salinity or hydrostatic pressure during the flood (Marta-Almeida et al., 2006). Near metamorphosis megalopae become more sensitive to chemical and physical settlement clues, attacting them towards settlement sites (Krimsky and Epifanio, 2008). Therefore, competent megalopae are in the bottom close to the estuary, being influenced by the tidal current, that provides a trapping mechanism, enhancing their supply during night flood tides (Reyns et al., 2007). This differential supply of settling larvae between new and full moon is likely promoted by an anti-predatory strategy displayed by these organisms (Moksnes et al., 2003), as moonlight is most intense during full moon nights, with larvae becoming more conspicuous to predators.

The larval supply of $C$. maenas in 2013 was the highest ever recorded in the study site (Domingues et al., 2011). From all supply events surveyed in the present study (258 events), only 12 events recorded megalopa supplies higher than $90^{\text {th }}$ percentile. This natural variation in megalopa supply, which was more pronounced in the year 2013, may be a consequence of larval phenotypic plasticity being favored by better trophic and/or abiotic scenarios in 2013 than 2012. Nevertheless, from an ecological point of view, an abnormal surge in megalopa supply may not be of particular relevance for this species, as intraspecific competition at early life stages post settlement is a key driver in the shaping of adult populations. Moksnes' experiments (2004a) demonstrated that 
competition for space promotes an unfavorable dispersal from nursery habitats, even when food is not a limiting factor for settling organisms of this species (Moksnes, 2004a). Furthermore, this competition for space favors agonistic behavior, with cannibalism being commonly recorded towards smaller and similar sized conspecifics (Moksnes, 2004a; Ramos, 2016). As such, an abnormally large pulse of megalopae invading a location may negatively affect the settlement success of conspecifics arriving in posterior events. Therefore, at least for C. maenas, it is likely that a more regular supply of a moderate number of megalopae during the settlement season may enhance recruitment in a more relevant way than abnormally high supply events. Several factors may have influenced the increase in the supply of megalopae in 2013, such as maternal effect and oceanographic forces. A previous work in the study area has confirmed that interannual and seasonal variability influence maternal investment and quality of ready-to-hatch embryos of marine invertebrates inhabiting highly dynamic environments (Rey et al., 2017). The contrasting environmental conditions experienced by females during brooding trigger physiological processes, enhancing energetic demand along embryonic development and promoting the consumption of fatty acids that will be essential in early larval stages (Rey et al., 2017). Furthermore, the occurrence of more constant and intense upwelling events during 2013, may play a relevant role in the interannual differences recorded in megalopa supplies (Rivera et al., 2013). The modelling study of Marta-Almeida et al. (2006) showed that diel vertical migration of megalopae induced the retention of larvae in the inner shelf during upwelling, consequently reducing larval waste towards the shelf and favoring their recruitment in coastal habitats (Domingues et al., 2012; Ospina-Alvarez et al., 2018). While a two-year comparison is not sufficient to predict larval supply patterns, the multiple-years analysis performed by Domingues et al. (2011) highlighted how the 
supply of megalopae in the study area can depend on several larval delivery

mechanisms that display significant shifts within and among years. The 12-year time series studied by Shanks (2013) revealed a strong relationship between oceanographic conditions and megalopa supply of Cancer magister. The author emphasized the influence of the timing of the spring transition in the annual return of megalopae and concluded that a steady upwelling through the summer promotes a more pronounced supply of megalopae to coastal habitats (Shanks, 2013). The key role played by the spring transition has already been highlighted by Domingues et al. (2011) for the larval supply of $C$. maenas in our study area. This study reported a better fit of supply data during periods characterized by a predominant upwelling regime (Domingues et al., 2011). It is worth noting that spring transition in 2013 occurred earlier than in 2012 and displayed more intense upwelling regimens. These features probably contributed to the differences recorded in the number and phenotype of megalopae supplied over these two consecutive years. Furthermore, while our study only recorded a significant effect of UI in the presence/absence model of 2013, this variable was also correlated with megalopa traits (see below). These findings suggest that match-mismatch dynamics (Cushing, 1990) play an important role in larval life histories in upwelling systems, influencing larval traits and shaping survival (Shanks, 2013; Wheeler et al., 2017). The differences identified in PLD over the two consecutive years are a consequence of the interaction between water temperature and food quality, which ultimately influences larval size (Byrne et al., 2011; Dawirs, 1985; Wheeler et al., 2017). Similarly, the decrease in PLD through the settlement period can be explained by the increase in SST (which overlaps with the spring-summer transition), which was more pronounced in 2012. During 2013, upwelling events were more intense, promoting a decrease in SST and increasing plankton productivity. Large-scale oceanographic 
processes stimulating upwelling events have been associated with higher levels of primary and secondary production, prompting an increase in regional productivity and recruitment of marine organism (Peteiro et al., 2011; Wheeler et al., 2017).

Furthermore, changes in wind forcing and oceanographic regimes (e.g. upwelling events) shape plankton communities (Bode et al., 2017; Wang et al., 2014), consequently impacting their trophic relationships and, finally, larval traits. Besides nutrition and larval size, water temperature influences metabolism, development, and growth (Anger, 2001; Boidron-Métairon, 1995; Bueno and López-Urrutia, 2012). In brachyuran crabs, it is well stablished that higher temperatures reduce the time of larval development. Therefore, larvae developing faster favor morphogenesis over somatic growth and commonly display smaller larval sizes (Anger, 2001). In this sense, higher seawater temperatures can promote a decrease in larval stage duration (PLD), resulting in a lower larval size (Anger, 1998; Wheeler et al., 2017). The progressive increase of SST along the settlement period of 2012 promoted a decrease in larval stage duration, while during the larval supply season of 2013, PLD remained constant. Additionally, contrasting conditions experienced during larval life can induce variations in larval phenotypic traits, such as size at settlement, which are carried-over into early benthic life (Pechenik et al., 1998; Rey et al., 2016). Contrasting larval traits over different larval supply periods may contribute to variations of adult population dynamics (Moksnes, 2004a, 2004b; Shanks, 2013). Further, taking into account the predatory nature of C. maenas, (Baeta et al., 2006; Leignel et al., 2014) the overall benthic community may be shaped by the shifts in phenotypic traits displayed by larvae over different supply events.

The high survival rates recorded for megalopae stocked in the laboratory under starvation confirm that most specimens only invade coastal habitats when they are 
physiologically fit to undergo such a dramatic event as metamorphosis (Anger, 2001; Rey et al., 2015). Therefore, most megalopae supplied to estuaries and coastal lagoons have already reached a point of reserve saturation, storing enough reserves to meet the energetic requirements of metamorphosis independently of food availability in the habitat being invaded (Anger, 2001). While the range of days and average TM was identical for both years surveyed in the present study, there was a lag in the preferential day to perform metamorphosis. In 2013 megalopae metamorphosed earlier than in 2012. This result suggests that megalopae supplied in 2013 invaded the coastal lagoon in a more advanced physiological stage than in 2012 and/or under better nutritional condition (Gonzalez-Gordillo et al., 2004). Under suboptimal trophic regimes, internal lipid reserves are mobilized to complete tissue growth and morphogenesis, thus allowing larvae to metamorphose if sufficient reserves have already been stored (Anger, 1998). In this way, megalopae invading the coastal lagoon in 2013 have likely experienced more favorable trophic conditions during their larval life (Wheeler et al., 2017). As explained above, upwelling regime stimulates plankton productivity, modify plankton communities and hence, shape larval trophic interactions in a quantitative and qualitative way (Bode et al., 2009; Lee et al., 2006; Sobrinho-Gonçalves et al., 2013). Studies addressing marine invertebrates have noted the relevant role that food quality, rather than food quantity (Toupoint et al., 2012; Wang et al., 2014), can play in the physiological condition of developing larvae. Therefore, a better quality diet provides more and better nutritional reserves to undergo the challenging transition between planktonic and benthic life (Boidron-Métairon, 1995; Toupoint et al., 2012). In this sense, controlled experiments in the laboratory have shown that the reserves accumulated during the planktonic larval phase have consequences at metamorphosis 
and young juvenile performance (Andrés et al., 2007; Calado and Leal, 2015; Phillips, 2002).

\section{Conclusions}

The present study highlights how the integration of field studies and laboratory experiments can allow researchers to better estimate interannual variations in larval supply and settlement success of marine invertebrates with bi-phasic life cycles. This work showed that physical forcing and larval supply present a complex relationship that ultimate influence the number and phenotype of successful settlers, with interannual patterns being difficult to be deciphered. Nevertheless, this study suggests that under weak upwelling events, SST strongly shapes the settlement of megalopae. On the other hand, megalopa settlement and fitness are conditioned by UI when settlement seasons overlap with stronger and more constant upwelling events. Our study calls for further research evaluating larval condition when supplied to coastal environments as well as when metamorphosing, in order to better estimate how larval traits promoted by contrasting oceanographic conditions can shape natural populations.

\section{Acknowledgements}

The authors acknowledge the University of Aveiro, Fundação para a Ciência e a Tecnologia (FCT, Portugal) and Ministério da Ciência e Tecnologia (MCTS) for the financial support to CESAM (UID/AMB/50017/2019), to FCT/MCTES through national funds, to QOPNA (FCT UID/QUI/00062/2019) through national founds and, where applicable, co-financed by the European Regional Development Fund (FEDER), within the Portugal 2020 Partnership Agreement. The present study was funded by FEDER through COMPETE and by National funding through FCT, within the research 
project NO RESET PTDC/BIA-BIC/116871/2010. This work was also supported by the Integrated Programme of SR\&TD “Smart Valorization of Endogenous Marine Biological Resources Under a Changing Climate” (Centro-01-0145-FEDER-000018), co-funded by Centro 2020 program, Portugal 2020, European Union, through the European Regional Development Fund. Felisa Rey (SFRH/BPD/115347/2016) and Gina Neto (SFRH/BD/ 88423/2012) were supported by FCT, Programa Operacional do Capital Humano (POCH) and European Union through European Social Fund (ESF). Felisa Rey acknowledges support from the Stimulus of Scientific Employment Individual Support, funded by national funds through FCT, I.P., within the scope of the project ExtraPhoto (CEECIND/00580/2017). The authors are also grateful to Instituto Hidrográfico Português to provide the sea surface temperature data in Porto de Leixões (Matosinhos, Portugal) and Bruna Silva and Daniela Ramos for their assistance in the laboratory. 


\section{References}

Andrés, M., Estévez, A., Rotllant, G., 2007. Growth, survival and biochemical composition of spider crab Maja brachydactyla (Balss, 1922) (Decapoda: Majidae) larvae reared under different stocking densities, prey:larva ratios and diets. Aquaculture 273, 494-502. https://doi.org/10.1016/j.aquaculture.2007.10.026

Anger, K., 2001. The Biology of Decapod Crustacean Larvae, Crustacean Issues. A.A. Balkema, Lisse, The Netherlands.

Anger, K., 1998. Patterns of growth and chemical composition in decapod crustacean larvae. Invertebr. Reprod. Dev. 33, 159-176.

Baeta, A., Cabral, H.N., Marques, J.C., Pardal, M.A., 2006. Feeding ecology of the green crab, Carcinus maenas (L., 1758) in a temperate estuary, Portugal. Crustaceana 79, 1181-1193.

Bode, A., Alvarez-Ossorio, M.T., Cabanas, J.M., Miranda, A., Varela, M., 2009. Recent trends in plankton and upwelling intensity off Galicia (NW Spain). Prog. Oceanogr. 83, 342-350. https://doi.org/10.1016/j.pocean.2009.07.025

Bode, A., Varela, M., Prego, R., Rozada, F., Santos, M.D., 2017. The relative effects of upwelling and river flow on the phytoplankton diversity patterns in the ria of $\mathrm{A}$ Coruña (NW Spain). Mar. Biol. 164, 93. https://doi.org/10.1007/s00227-017$3126-9$

Boidron-Métairon, I., 1995. Larval nutrition, in: McEdward, L. (Ed.), Ecology of Marine Invertebrate Larvae. CRC Press, Boca Raton, Florida, pp. 223-248. Broekhuysen, G.J., 1936. On development, growth and distribution of Carcinus maenas (L.). Arch. Neerl. Zool. 2, 257-399.

Bueno, J., López-Urrutia, Á., 2012. The offspring-development-time/offspring-number 
trade-off. Am. Nat. 179, E196-E203. https://doi.org/10.1086/665652

Byrne, M., Selvakumaraswamy, P., Ho, M.A., Woolsey, E., Nguyen, H.D., 2011. Sea urchin development in a global change hotspot, potential for southerly migration of thermotolerant propagules. Deep. Res. Part Ii-Topical Stud. Oceanogr. 58, 712719. https://doi.org/10.1016/j.dsr2.2010.06.010

Calado, R., Leal, M.C., 2015. Trophic ecology of benthic marine invertebrates with biphasic life cycles: What are we still missing? Adv. Mar. Biol. 71, 1-70. https://doi.org/0.1016/bs.amb.2015.07.001

Crothers, J., 1967. The biology of the shore crab Carcinus maenas (L.) 1. The background-anatomy, growth and life history. F. Stud. 2, 407-434.

Cushing, D.H., 1990. Plankton production and year-class strength in fish populations an update of the match mismatch hypothesis. Adv. Mar. Biol. 26, 249-293.

Dawirs, R.R., 1985. Temperature and larval development of Carcinus maenas (Decapoda) in the laboratory; predictions of larval dynamics in the sea. Mar. Ecol. Prog. Ser. 24, 297-302.

Dias, J.M., Lopes, J.F., Dekeyser, I., 2000. Tidal propagation in Ria de Aveiro Lagoon, Portugal. Phys. Chem. Earth, Part B Hydrol. Ocean. Atmos. 25, 369-374. https://doi.org/10.1016/S1464-1909(00)00028-9

Domingues, C.P., Almeida, M.J., Dubert, J., Nolasco, R., Cordeiro, N., Waap, S., Sequeira, A., Tavares, S., Queiroga, H., 2011. Supply of crab larvae to an estuary in the eastern Atlantic upwelling system exhibits predictable and haphazard variation at different temporal scales. Mar. Ecol. Prog. Ser. 425, 113-124. https://doi.org/10.3354/Meps08992

Domingues, C.P., Nolasco, R., Dubert, J., Queiroga, H., 2012. Model-derived dispersal pathways from multiple source populations explain variability of invertebrate 
larval supply. PLoS One 7, e35794. https://doi.org/10.1371/journal.pone.0035794

Fiuza, A.F.G., Hamann, M., Ambar, I., del Rio, G.D., González, N., Cabanas, J.M., 1998. Water masses and their circulation off western Iberia during May 1993. Deep. Res. Part I-Oceanographic Res. Pap. 45, 1127-1160. https://doi.org/10.1016/S0967-0637(98)00008-9

Fowler, A.E., Gerner, N. V., Sewell, M. a., 2010. Temperature and salinity tolerances of Stage 1 zoeae predict possible range expansion of an introduced portunid crab, Charybdis japonica, in New Zealand. Biol. Invasions 13, 691-699. https://doi.org/10.1007/s10530-010-9860-2

Gillooly, J.F., Charnov, E.L., West, G.B., Savage, V.M., Brown, J.H., 2002. Effects of size and temperature on developmental time. Nature 417, 70-73.

Giménez, L., 2011. Exploring mechanisms linking temperature increase and larval phenology: The importance of variance effects. J. Exp. Mar. Bio. Ecol. 400, 227235. https://doi.org/Doi 10.1016/J.Jembe.2011.02.036

Giménez, L., 2010. Relationships between habitat conditions, larval traits, and juvenile performance in a marine invertebrate. Ecology 91, 1401-1413.

Gimenez, L., Torres, G., Pettersen, A., Burrows, M., Estevez, A., Jenkins, S., 2017. Scale-dependent natural variation in larval nutritional reserves in a marine invertebrate: implications for recruitment and cross-ecosystem coupling. Mar. Ecol. Prog. Ser. 570, 141-155. https://doi.org/10.3354/meps12081

Gonzalez-Gordillo, J.I., Rodriguez, A., Queiroga, H., 2004. Characterization of the megalopal premoult stages of the green crab, Carcinus maenas (Decapoda, Portunidae), from laboratory culture. J. Crustac. Biol. 24, 502-510.

González-Nuevo, G., Gago, J., Cabanas, J.M., 2014. Upwelling index: a powerful tool for marine research in the NW Iberian upwelling system. J. Oper. Oceanogr. 7, 
47-57. https://doi.org/10.1080/1755876X.2014.11020152

Guisande, C., Cabanas, J., Vergara, A., Riveiro, I., 2001. Effect of climate on recruitment success of Atlantic Iberian sardine Sardina pilchardus. Mar. Ecol. Prog. Ser. 223, 243-250. https://doi.org/10.3354/meps223243

Huthnance, J.M., Van Aken, H.M., White, M., Barton, E.D., Le Cann, B., Coelho, E.F., Fanjul, E.A., Miller, P., Vitorino, J., 2002. Ocean margin exchange - water flux estimates. J. Mar. Syst. 32, 107-137. https://doi.org/10.1016/S09247963(02)00034-9

Krimsky, L.S., Epifanio, C.E., 2008. Multiple cues from multiple habitats: Effect on metamorphosis of the Florida stone crab, Menippe mercenaria. J. Exp. Mar. Bio. Ecol. 358, 178-184. https://doi.org/Doi 10.1016/J.Jembe.2008.02.010

Lee, R.F., Hagen, W., Kattner, G., 2006. Lipid storage in marine zooplankton. Mar. Ecol. Prog. Ser. 307, 273-306.

Leignel, V., Stillman, J.H., Baringou, S., Thabet, R., Metais, I., 2014. Overview on the European green crab Carcinus spp. (Portunidae, Decapoda), one of the most famous marine invaders and ecotoxicological models. Environ. Sci. Pollut. Res. 21, 9129-9144. https://doi.org/10.1007/s11356-014-2979-4

Lyons, L.J., Riordan, R.M.O., Cross, T.F., Culloty, S.C., 2012. Reproductive biology of the shore crab Carcinus maenas (Decapoda, Portunidae): a macroscopic and histological view. Invertebr. Reprod. Dev. 56, 144-156.

Marshall, D.J., Morgan, S.G., 2011. Ecological and evolutionary consequences of linked life-history stages in the sea. Curr. Biol. 21, R718-R725. https://doi.org/10.1016/J.Cub.2011.08.022

Marta-Almeida, M., Dubert, J., 2006. The structure of tides in the Western Iberian region. Cont. Shelf Res. 26, 385-400. https://doi.org/Doi 
10.1016/J.Csr.2005.11.011

Marta-Almeida, M., Dubert, J., Peliz, A., Queiroga, H., 2006. Influence of vertical migration pattern on retention of crab larvae in a seasonal upwelling system. Mar. Ecol. Prog. Ser. 307, 1-19.

Moksnes, P.-O., 2004a. Interference competition for space in nursery habitats: densitydependent effects on growth and dispersal in juvenile shore crabs Carcinus maenas. Mar. Ecol. Prog. Ser. 281, 181-191.

Moksnes, P.-O., 2004b. Self-regulating mechanisms in cannibalistic populations of juvenile shore crabs Carcinus maenas. Ecology 85, 1343-1354.

Moksnes, P.-O., Hedvall, O., Reinwald, T., 2003. Settlement behavior in shore crabs Carcinus maenas: why do postlarvae emigrate from nursery habitats? Mar. Ecol. Ser. 250, 215-230.

Morgan, S., White, J., McAfee, S., Gaines, S., Schmitt, R., 2011. Weak synchrony in the timing of larval release in upwelling regimes. Mar. Ecol. Prog. Ser. 425, 103112. https://doi.org/10.3354/meps08969

Moser, S.M., Macintosh, D.J., 2001. Diurnal and lunar patterns of larval recruitment of brachyura into a mangrove estuary system in Ranong Province, Thailand. Mar. Biol. https://doi.org/10.1007/s002270000502

Ospina-Alvarez, A., Weidberg, N., Aiken, C., Navarrete, S., 2018. Larval transport in the upwelling ecosystem of central Chile: The effects of vertical migration, developmental time and coastal topography on recruitment. Prog. Oceanogr. 168, 82-99. https://doi.org/10.1016/j.pocean.2018.09.016

Otero, J., Álvarez-Salgado, X., Gonzalez, A., Gilcoto, M., Guerra, A., 2009. Highfrequency coastal upwelling events influence Octopus vulgaris larval dynamics on the NW Iberian shelf. Mar. Ecol. Prog. Ser. 386, 123-132. 
Paula, J., Dray, T., Queiroga, H., 2001. Interaction of offshore and inshore processes controlling settlement of brachyuran megalopae in Saco mangrove creek, Inhaca Island (South Mozambique). Mar. Ecol. Ser. 215, 251-260.

Pechenik, J.A., 2018. Latent Effects : Surprising Consequences of Embryonic and Larval Experience on Life after Metamorphosis, in: Carrier, T.J., Reitzel, A.M., Heyland, A. (Eds.), Evolutionary Ecology of Marine Invertebrate Larvae. Oxford University Press, pp. 208-225.

https://doi.org/10.1093/oso/9780198786962.003.0014

Pechenik, J.A., 2006. Larval experience and latent effects - metamorphosis is not a new beginning. Integr. Comp. Biol. 46, 323-333. https://doi.org/10.1093/Icb/Icj028

Pechenik, J.A., Wendt, D.E., Jarrett, J.N., 1998. Metamorphosis is not a new beginning. Bioscience 48, 901-910.

Peliz, A., Rosa, T.L., Santos, A.M.P., Pissarra, J.L., 2002. Fronts, jets, and counterflows in the Western Iberian upwelling system. J. Mar. Syst. 35, 61-77.

Peteiro, L.G., Labarta, U., Fernández-Reiriz, M.J., Álvarez-Salgado, X.A., Filgueira, R., Piedracoba, S., 2011. Influence of intermittent-upwelling on Mytilus galloprovincialis settlement patterns in the Ría de Ares-Betanzos. Mar. Ecol. Prog. Ser. 443, 111-127. https://doi.org/10.3354/meps09433

Peters-Didier, J., Sewell, M.A., 2019. The role of the hyaline spheres in sea cucumber metamorphosis: lipid storage via transport cells in the blastocoel. Evodevo 10, 8. https://doi.org/10.1186/s13227-019-0119-4

Phillips, N.E., 2006. Natural variability in size and condition at settlement of 3 species of marine invertebrates. Integr. Comp. Biol. 46, 598-604. https://doi.org/10.1093/icb/ic1008

Phillips, N.E., 2002. Effects of nutrition-mediated larval condition on juvenile 
performance in a marine mussel. Ecology 83, 2562-2574.

Pineda, J., Reyns, N., Starczak, V., 2009. Complexity and simplification in understanding recruitment in benthic populations. Popul. Ecol. 51, 17-32. https://doi.org/Doi 10.1007/S10144-008-0118-0

Queiroga, H., Almeida, M., Alpuim, T., Flores, A., Francisco, S., González-Gordillo, I., Miranda, A., Silva, I., Paula, J., 2006. Tide and wind control of megalopal supply to estuarine crab populations on the Portuguese west coast. Mar. Ecol. Prog. Ser. 307, 21-36.

Ramos, D., 2016. Intraspecific agonistic behaviour during settlement events of a marine invertebrate with a biphasic life cycle. University of Aveiro.

Reis-Santos, P., Tanner, S.E., Vasconcelos, R.P., Elsdon, T.S., Cabral, H.N., Gillanders, B.M., 2013. Connectivity between estuarine and coastal fish populations: Contributions of estuaries are not consistent over time. Mar. Ecol. Prog. Ser. 491, 177-186. https://doi.org/10.3354/meps10458

Rey, F., Domingues, M.R.M., Domingues, P., Rosa, R., Orgaz, M.D.M., Queiroga, H., Calado, R., 2017. Effect of maternal size, reproductive season and interannual variability in offspring provisioning of Carcinus maenas in a coastal lagoon. Estuaries and Coasts 40, 1732-1743. https://doi.org/10.1007/s12237-017-0235-0

Rey, F., Neto, G.M.S., Brandão, C., Ramos, D., Silva, B., Rosa, R., Queiroga, H., Calado, R., 2016. Contrasting oceanographic conditions during larval development influence the benthic performance of a marine invertebrate with a biphasic life cycle. Mar. Ecol. Prog. Ser. 546, 135-146. https://doi.org/10.3354/meps11629

Rey, F., Neto, G.M.S., Rosa, R., Queiroga, H., Calado, R., 2015. Laboratory trials reveal that exposure to extreme raining events prior to metamorphosis affect the 
post-settlement performance of an estuarine crab. Estuar. Coast. Shelf Sci. 154, 179-183. https://doi.org/10.1016/j.ecss.2015.01.005

Reyns, N.B., Eggleston, David, B., Luettich, R.A., 2007. Dispersal dynamics of postlarval blue crabs, Callinectes sapidus, within a wind-driven estuary. Fish. Oceanogr. 16, 257-272. https://doi.org/10.1111/j.1365-2419.2006.00420.x

Rivera, A., Weidberg, N., Pardiñas, A.F., González-Gil, R., García-Flórez, L., Acuña, J.L., 2013. Role of upwelling on larval dispersal and productivity of gooseneck barnacle populations in the Cantabrian sea: Management implications. PLoS One 8. https://doi.org/10.1371/journal.pone.0078482

Sewell, M.A., 2005. Utilization of lipids during early development of the sea urchin Evechinus chloroticus. Mar. Ecol. Prog. Ser. 304, 133-142. https://doi.org/10.3354/meps304133

Shanks, A.L., 2013. Atmospheric forcing drives recruitment variation in the Dungeness crab (Cancer magister), revisited. Fish. Oceanogr. 22, 263-272. https://doi.org/10.1111/fog.12020

Shanks, A.L., Brink, L., 2005. Upwelling, downwelling, and cross-shelf transport of bivalve larvae : test of a hypothesis. Mar. Ecol. Prog. Ser. 302, 1-12.

Shima, J., Swearer, S., 2009. Larval quality is shaped by matrix effects: implications for connectivity in a marine metapopulation. Ecology 90, 1255-1267.

Sobrinho-Gonçalves, L., Moita, M.T., Garrido, S., Cunha, M.E., 2013. Environmental forcing on the interactions of plankton communities across a continental shelf in the Eastern Atlantic upwelling system. Hydrobiologia 713, 167-182. https://doi.org/10.1007/s10750-013-1500-2

Teixeira, I.G., Figueiras, F.G., Crespo, B.G., Piedracoba, S., 2011. Microzooplankton feeding impact in a coastal upwelling system on the NW Iberian margin: The Ría 
de Vigo. Estuar. Coast. Shelf Sci. 91, 110-120.

https://doi.org/10.1016/j.ecss.2010.10.012

Torres, G., Giménez, L., Pettersen, A.K., Bue, M., Burrows, M.T., Jenkins, S.R., 2016. Persistent and context-dependent effects of the larval feeding environment on post-metamorphic performance through the adult stage. Mar. Ecol. Prog. Ser. 545, 147-160. https://doi.org/10.3354/meps 11586

Toupoint, N., Gilmore-Solomon, L., Bourque, F., Myrand, B., Pernet, F., Olivier, F., Tremblay, R., 2012. Match/mismatch between the Mytilus edulis larval supply and seston quality: effect on recruitment. Ecology 93, 1922-1934. https://doi.org/10.1890/11-1292.1

Vasconcelos, R.P., Reis-Santos, P., Maia, A., Fonseca, V., França, S., Wouters, N., Costa, M.J., Cabral, H.N., 2010. Nursery use patterns of commercially important marine fish species in estuarine systems along the Portuguese coast. Estuar. Coast. Shelf Sci. 86, 613-624. https://doi.org/10.1016/j.ecss.2009.11.029

Wang, M., O’Rorke, R., Waite, a. M., Beckley, L.E., Thompson, P., Jeffs, a. G., 2014. Fatty acid profiles of phyllosoma larvae of western rock lobster (Panulirus cygnus) in cyclonic and anticyclonic eddies of the Leeuwin Current off Western Australia. Prog. Oceanogr. 122, 153-162. https://doi.org/10.1016/j.pocean.2014.01.003

Wheeler, S.G., Anderson, T.W., Bell, T.W., Morgan, S.G., Hobbs, J.A., 2017. Regional productivity predicts individual growth and recruitment of rockfishes in a northern California upwelling system. Limnol. Oceanogr. 62, 754-767. https://doi.org/10.1002/1no.10458 


\section{Running Head}

Oceanographic shaping of larval traits

Title

Supply and larval traits at metamorphosis of a coastal marine invertebrate with a bi-phasic life cycle under contrasting oceanographic conditions

Felisa Rey ${ }^{1,2 *}$, Gina M. Silva Neto ${ }^{1}$, Juan Bueno-Pardo ${ }^{3}$, Regina Bispo ${ }^{4}$ and Ricardo Calado $^{1 *}$

${ }^{1}$ Departamento de Biologia \& CESAM \& ECOMARE, Universidade de Aveiro, Campus Universitário de Santiago, 3810-193 Aveiro, Portugal

${ }^{2}$ Departamento de Química \& QOPNA, Universidade de Aveiro, Campus

Universitário de Santiago, 3810-193 Aveiro, Portugal

${ }^{3}$ Ifremer, STH/LBH, B.P. 70, Plouzané 29280, France

${ }^{4}$ Departamento de Matemática, Faculdade de Ciências e Tecnologia, Universidade Nova de Lisboa, 2829-516 Caparica

e-mail address:

Felisa Rey*: felisa.rey@gmail.com

Gina Neto: ginaneto11@gmail.com

Juan Bueno-Pardo: jbuenopardo@gmail.com

Regina Bispo: regina.b.bispo@gmail.com

Ricardo Calado*: rjcalado@hotmail.com 


\section{Highlights}

- Larval supply in coastal habitats is influenced by oceanographic processes

- Moon cycle exerts a strong influence in coastal supply of megalopae

- Higher megalopa supply was recorded during spring tides

- Oceanographic processes stimulating upwelling promote variations in larval traits

- Phenotypic larval traits condition larval performance at metamorphosis 
Supply and larval traits at metamorphosis of a coastal marine invertebrate with a bi-phasic life cycle under contrasting oceanographic conditions

Felisa Rey ${ }^{1,2 *}$, Gina M. Silva Neto ${ }^{1}$, Juan Bueno-Pardo ${ }^{3,4}$, Regina Bispo ${ }^{5}$ and Ricardo Calado $^{1 *}$

${ }^{1}$ Departamento de Biologia \& CESAM \& ECOMARE, Universidade de Aveiro, Campus Universitário de Santiago, 3810-193 Aveiro, Portugal

${ }^{2}$ Departamento de Química \& QOPNA, Universidade de Aveiro, Campus Universitário de Santiago, 3810-193 Aveiro, Portugal

${ }^{3}$ Ifremer, STH/LBH, B.P. 70, Plouzané 29280, France

${ }^{4}$ Present address: Campus de Gambelas, Centro de Ciências do Mar (CCMAR), Universidade do Algarve, 8005-139 Faro, Portugal

${ }^{5}$ Departamento de Matemática, Faculdade de Ciências e Tecnologia, Universidade Nova de Lisboa, 2829-516 Caparica, Portugal

e-mail address:

Felisa Rey*: felisa.rey@gmail.com

Gina Neto: ginaneto11@gmail.com

Juan Bueno-Pardo: jbuenopardo@gmail.com

Regina Bispo: regina.b.bispo@gmail.com

Ricardo Calado*: rjcalado@hotmail.com 


\section{Conflict of interest}

The authors declare that they have no competing interests. 